Pak. j. sci. ind. res. Ser. A: phys. sci. 2017 60(1) 29-33

\title{
Qualitative Analysis of Siro-spun and Two Fold Yarns Tensile Properties under the Influence of Twist Factor
}

\author{
Muhammad Qamar Tusief ${ }^{a} *$, Nasir Mahmood ${ }^{a}$, Nabeel Amin ${ }^{b}$ and Akmal Saeed \\ ${ }^{a}$ Department of Fibre \& Textile Technology, University of Agriculture Faisalabad, Pakistan \\ ${ }^{\mathrm{b}} \mathrm{S}$ chool of Textile and Design, University of Management and Technology, Lahore, Pakistan
}

(received August 22, 2016; revised September 26, 2016; accepted September 30, 2016)

\begin{abstract}
Siro yarns are spun from two separate roving of same type of materials. Similarly in textile arts, folding is a process used to create a strong and balance yarn by putting together two separate yarns. Hence, this research study was carried to analyse the quality of Siro-spun and two fold yarns under the influence of twist factor with special reference to their tensile properties. The results disclosed better tensile properties of yarn made from Siro spinning technique as compared to two plied yarn. This indicates the supremacy of Siro-spun yarn over two fold yarn. These findings enhance the fact that Siro spinning technique produces better quality yarn as compared to conventional ring spinning technique.
\end{abstract}

Keywords: Siro-spun twist multiplier, two fold yarn, yarn tensile properties

\section{Introduction}

Tensile properties of yarns are one of the most important characteristics desired by the spinners. These properties play significant role in determining the quality of the end product. In addition to raw material (fibre) characteristics, different spinning techniques and twist factor have vital role in defining the tensile properties of the yarn. Siro spinning is a technique which is being predicted to have profound influence on the yarn spinning industry. Siro-spun yarns are manufactured on a conventional ring frame by feeding two roving, drafted simultaneously into the apron zone at a predetermined separation. The two strands are twisted together to form a two ply structure, when emerge from the nip point of the front rollers. This is an important spinning technique invented by the laboratories of the Commonwealth Science International Research Organization (CSIRO), Division of Textile Industry in Australia (Xuzhong et al., 2015; Huo, 2008). A number of investigations have been made during the last two decades to analyse the properties of Siro-spun yarns and their edges over the conventional yarns. It has been depicted from all these studies that Siro-spun yarns have better properties in many ways as compared to the conventional yarns (Soltani, 2012). Most of these researches have covered the yarn appearance and mechanical properties in comparison with conventional ring spun yarn. However, there exist great research

\footnotetext{
*Author for correspondence; E-mail: qamartosif@yahoo.com
}

deficiency in the area of comparing quality parameters of Siro-spun yarn with two fold yarn.

In the textile fields, folding is a process, which is used to produce a strong, balanced yarn. It is made by taking two or more strands of yarn that each has a twist to them and putting them together. The combined strands are twisted in the opposite direction than that in which they were spun. Many newness yarns are made by using special plying techniques to produce their special effects. Textile industry extensively uses the folded yarns. Folded yarns are used in many woven and knitted fabrics (Bashir, 2010). Folded yarns are better in quality than single yarns because in single yarns in order to improve their strength and appearance some kind of sizing material is applied but in case of folded yarns sizing can be eliminated. The folded yarns get desired strength and appearance due to the folding of two single yarns which make them to bind each other completely reducing the hairiness of the resulting yarn and increase its abrasion resistance property (Palaniswamy and Mohamed, 2006).

The twist of yarns and threads influences their form and structure. This feature creates the thread's properties, and at the same time is conclusive regarding the processing throughout. Yarn folding that is twisting together some component fibre streams, causes an increase in tenacity, a lowering of the bending stiffness, a decrease in the linear mass irregularity, an increase in the abrasion and lowering of the thread's tendency 
to pilling formation. Consequential to these favourable circumstances, twisting positively influences the thread's making throughout and the barrier ability of the fabrics made from such a yarns (Rosiak and Przybyl, 2004).

Hence, keeping in view the above interface of Sirospun and two fold yarns, the present research study was planned to explore the qualitative comparison of the tensile properties of these yarns under the influence of various twist factors. This could be helpful to set an optimum quality level of these two yarns for their better tensile properties to decide the best use of these yarns in making good quality end products.

\section{Materials and Methods}

The cotton yarn samples of two types Y1=Siro-spun yarn and $\mathrm{Y} 2=$ two fold yarn were made for the same count of $20 \mathrm{~s}$ at three twist levels $\mathrm{T} 1=3.5, \mathrm{~T} 2=3.7$ and $\mathrm{T} 3=3.9$, respectively. The folded twist of the two ply was inserted equal to that of its corresponding Siroyarn, the folded twist of two ply was set at $70 \%$ of that of the single yarn as suggested by Cheng and Yuen (1997). Yarn samples so made were tested for their tensile properties (single yarn strength, rupture per kilometer, elongation percentage) using the following testing instrument and method.

Tensile properties of yarn. Tensile properties i.e., single end strength, elongation and rupture per kilometer were observed with Uster Tensorapid-3 which works on the principle of constant rate of extension (CRE). The principle describes the fact that the moving clamps are displaced at constant velocity as a result of which the specimen caught in between the stationary and moving clamps extended by a constant rate. The breaking tenacity was measured from the maximum force which was applied anywhere between the beginning of the test and the final rupture of the specimen. The breaking elongation of yarn was measured from the clamp displacement at the point of peak force. The procedure was adopted according to the ASTM (American Society for Testing and Materials) Standard for tensile properties of yarns by the single strand method D 2256-02 (ASTM, 2008).

Analysis of data. Duncan's multiple range test was applied in the analysis of variance of data for testing the differences among various quality characteristics as suggested by Montgomery (2009) applying statistical package for social sciences (SPSS) using microcomputer statistical programme.

\section{Results and Discussion}

Single yarn strength (g). The statistical analysis of variance and comparison of individual treatment means of the data regarding single yarn strength is given in Table 1 and 1(a), respectively. The results indicates that the main effects of yarn type $(\mathrm{Y})$ and twist multiplier (T) were found significant while the interaction effect of $(\mathrm{Y} \times \mathrm{T})$ was non-significant at $0.05 \%$ level of significance.

As the interaction effect is non-significant, it leads to the multiple means comparison of main significant effects. As this experiment was done under control conditions so the chances of error were less. The Duncan's multiple range test was selected for mean comparison of treatments.

Duncan's multiple range test and the comparison for individual mean values regarding single yarn strength under different yarn types are given in Table 1(a) which indicate a maximum value of single yarn strength for Siro-spun yarn (Y1) i.e., $476.91 \mathrm{~g}$ followed by $469.85 \mathrm{~g}$ i.e., for the two fold yarn (Y2), respectively. These findings are well supported by a previous study that the Siro-spun yarn was stronger than two plied yarn at all twist multipliers (Sun and Cheng, 2000). Moreover, in another research study it was concluded that Siro-spun yarns had better yarn tenacity and yarn elongation (\%) values (Temel and Celik, 2010).

Table. 1 Analysis of variance for single yarn strength

\begin{tabular}{llllll}
\hline \hline S.O.V & D.F. & S.S. & M.S. & F. value & P \\
\hline $\mathrm{T}$ & 2 & 54.611 & 27.3057 & 1164.42 & $0.000^{* *}$ \\
$\mathrm{Y}$ & 1 & 74.765 & 74.7654 & 3188.29 & $0.000^{* *}$ \\
$\mathrm{Y} \times \mathrm{T}$ & 2 & 0.041 & 0.020 & 0.89 & $0.005963^{\mathrm{N} . S}$ \\
Error & 2 & 0.047 & 0.0235 & - & - \\
Total & 7 & 129.464 & - & - & - \\
\hline \hline
\end{tabular}

S.O.V = Source of variance; D.F $=$ Degree of freedom; $S . S=$ Sum of square; $\mathrm{M} . \mathrm{S}=$ Mean square; $\mathrm{P}=$ Probability; F.value $=\mathrm{F}$ ratio value; $* *=$ Highly significant; $*=$ Significant; N.S

$=$ Non Significant

Table 1a. Comparison of individual treatment means for single yarn strength $(\mathrm{g})$

\begin{tabular}{llll}
\hline \hline Yarn Types (Y) & Means & Twist Multiplier (T) & Means \\
\hline Y1 & $476.91^{\mathrm{a}}$ & T1 & $469.86^{\mathrm{c}}$ \\
Y2 & $469.85^{\mathrm{b}}$ & T2 & $473.07^{\mathrm{b}}$ \\
& & T3 & $477.23^{\mathrm{a}}$ \\
\hline \hline
\end{tabular}

$\overline{\text { Any two values not sharing a letter in common differ }}$ significantly at 0.05 level of probability. 


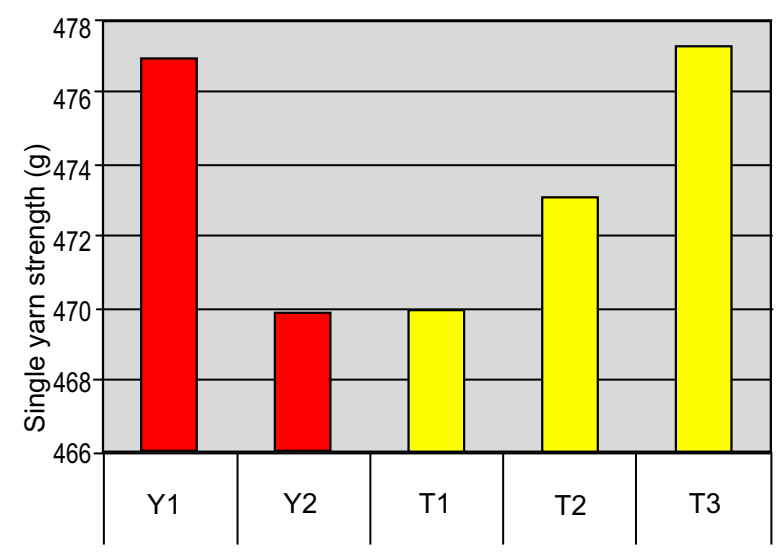

Fig. 1. Graphical representation of individual mean values for single yarn strength $(\mathrm{g})$.

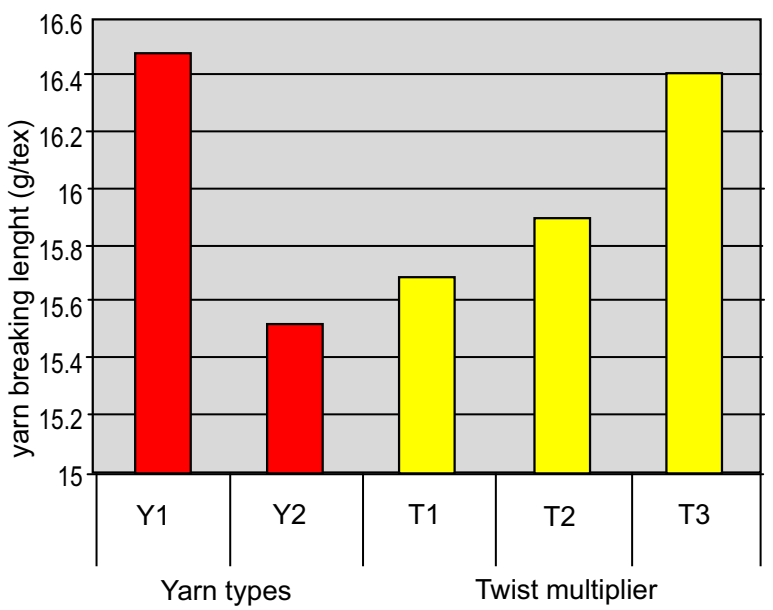

Fig. 2. Graphical representation of mean values for yarn breaking length (g/tex).

The comparison for individual mean values regarding single yarn strength for different twist multiplier by applying Duncan's multiple range test is given in Table 1a and elaborated in Fig. 1. The results show that the highest value regarding single yarn strength was recorded for twist multiplier T3(3.9) i.e., $477.23 \mathrm{~g}$ followed by $473.07 \mathrm{~g}$ and $469.86 \mathrm{~g}$ for $\mathrm{T} 2(3.7)$ and $\mathrm{T} 1(3.5)$, respectively. The result of these values discloses a significant difference. It is clear from the results that the single yarn strength increased with the increase in twist in the yarn. These results are in line with the findings that the tenacity of yarn increased with the twist multiplier when it did not exceed the optimum twist multiplier (Lei, 2003). Similarly, in another study it was found that as the twist level increased, the yarn strength increased up to a certain level, beyond which the increase in twist actually decreased the strength of staple yarn (Palaniswamy and Mohamed, 2006).

Yarn breaking length $\{$ RKM value (g/tex) $\}$. The statistical analysis of variance and comparison of individual treatment means of the data regarding breaking strength (RKM) is given in Table 2 and 2(a), respectively. The results indicate that the effect of yarn types (Y) and twist multiplier (T) are significant while the effect of interaction between the $(\mathrm{Y} \times \mathrm{T})$ is found to be non- significant on yarn breaking length.

Duncan's multiple range test and comparison for individual mean values regarding yarn breaking length for different yarn types is presented in Table 2(a) which indicates that the maximum value of RKM for Sirospun yarn (Y1) is $16.48 \mathrm{~g} /$ tex followed by $15.53 \mathrm{~g} /$ tex for two fold yarn (Y2), respectively. These results depict that RKM value for Siro-yarn is more than that of two fold yarn. These results get support from the findings that the breaking strength of Siro-spun yarn was higher than that of the two fold yarns of equivalent linear density due to the particular Siro-yarn structure in which fibres are being more firmly bound within the yarn structure. The twisted strands of the drafted fibres caused some surfaces fibres to be trapped into the Siro yarn so as to increase the inter fibre cohesion in the yarn which withstand higher breaking forces (Cheng and Yuen,

Table 2. Analysis of variance for yarn breaking length

\begin{tabular}{llllll}
\hline \hline S.O.V & D.F. & S.S. & M.S. & F. value & P \\
\hline $\mathrm{Y}$ & 1 & 1.36327 & 1.36327 & 1573.00 & $0.0006^{*}$ \\
$\mathrm{~T}$ & 2 & 0.56493 & 0.28247 & 325.92 & $0.0031^{*}$ \\
$\mathrm{Y} \times \mathrm{T}$ & 2 & 0.00261 & 0.001305 & 1.5 & $0.15931^{\text {N.S }}$ \\
Error & 2 & 0.00173 & 0.00087 & - & - \\
Total & 7 & 1.93254 & - & - & - \\
\hline \hline
\end{tabular}

S.O.V = Source of variance; D.F $=$ Degree of freedom; $\mathrm{S} . \mathrm{S}=$ Sum of square; $\mathrm{M} . \mathrm{S}=$ Mean square; $\mathrm{P}=$ Probability; F.value $=\mathrm{F}$ ratio value $*$ $*$ Significant N $. \mathrm{S}=$ Non significant

Table 2a. Comparison of individual treatment means for yarn breaking length (g/tex)

\begin{tabular}{llll}
\hline \hline Yarn types (Y) & Means & Twist multiplier (T) & Means \\
\hline Y1 & $16.480 \mathrm{a}$ & T1 & $15.690^{\mathrm{c}}$ \\
Y2 & $15.527 \mathrm{~b}$ & T2 & $15.900^{\mathrm{b}}$ \\
& & T3 & $16.420^{\mathrm{a}}$ \\
\hline
\end{tabular}

Any two values not sharing a letter in common differ significantly at 0.05 level of probability 
Table 3. Analysis of variance for yarn elongation

\begin{tabular}{llllll}
\hline \hline S.O.V & D.F. & S.S. & M.S. & F. value & P \\
\hline $\mathrm{Y}$ & 1 & 0.20167 & 0.20167 & 12100.0 & $0.0001^{*}$ \\
$\mathrm{~T}$ & 2 & 0.08923 & 0.04462 & 2677.00 & $0.0004^{*}$ \\
$\mathrm{Y} \times \mathrm{T}$ & 2 & .000072 & .000036 & 1.8 & $0.3217^{\mathrm{N} . \mathrm{S}}$ \\
Error & 2 & 0.00003 & 0.00002 & - & - \\
Total & 7 & 0.29100 & - & - & - \\
\hline \hline
\end{tabular}

S.O.V = Source of variance; D.F = Degree of freedom; $\mathrm{S} . \mathrm{S}=$ Sum of square; M.S= Mean square; $\mathrm{P}=$ Probability; F.value $=\mathrm{F}$ ratio value; $*=$ Significant N.S $=$ Non significant

Table 3a. Comparison of individual treatment means for yarn elongation (\%)

\begin{tabular}{lllr}
\hline \hline Yarn types (Y) & Means & Twist multiplier (T) & Means \\
\hline Y1 & $6.4800^{\mathrm{a}}$ & T1 & $6.18^{\mathrm{c}}$ \\
Y2 & $6.1133^{\mathrm{b}}$ & T2 & $6.245^{\mathrm{b}}$ \\
& & T3 & $6.465^{\mathrm{a}}$ \\
\hline \hline
\end{tabular}

$\overline{\text { Any two values not sharing a letter in common differ }}$ significantly at 0.05 level of probability.

1997). In the same lines it was observed that the Sirospun yarn was stronger with more yarn tenacity and elongation \% than two plied yarn at all twist multipliers (Temel and Celik, 2010; Sun and Cheng, 2000).

Duncan's multiple range test and the comparison for individual mean values regarding yarn breaking length at different twist multiplier is given in Table $2 \mathrm{a}$ and further illustrated in Fig. 2. It is clear from the findings that the highest value of yarn breaking strength (RKM)

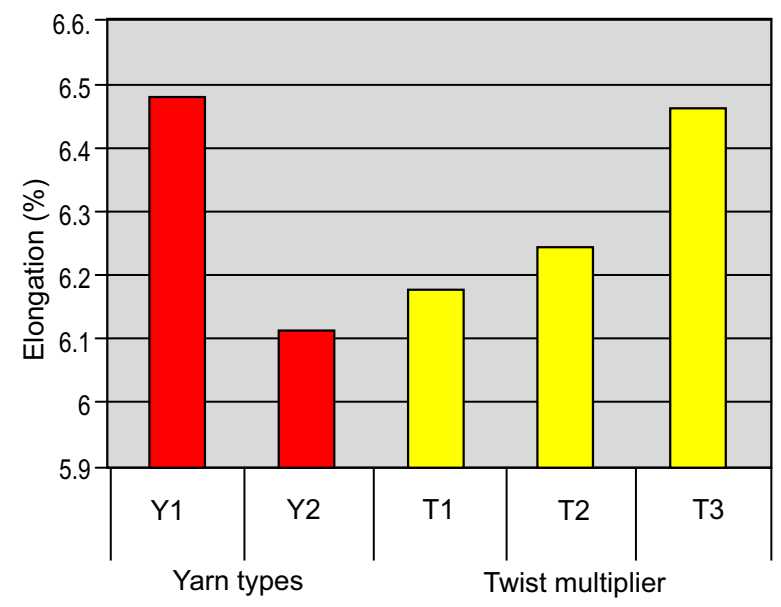

Fig. 3. Graphical representation of individual mean values for elongation (\%) i.e., $16.42 \mathrm{~g}$ /tex is recorded for T3 followed by 15.90 and $15.69 \mathrm{~g} /$ tex for $\mathrm{T} 2$ and $\mathrm{T} 1$, respectively. These results differ significantly from each other. It is clear from the observation that as the yarn twist increased, the RKM value increased. These results are in line with the findings that the tenacity of yarn increased with the twist multiplier when it did not exceed the optimum twist multiplier (Lei, 2003).

Yarn elongation \%. The statistical analysis of variance and comparison of individual treatment means of the data regarding yarn elongation (\%) is given in Table 3 and 3(a), respectively. The results indicate that the effects of twist multiplier (T) and the yarn types $(\mathrm{Y})$ on elongation of yarn are significant while the effect of interaction of $(\mathrm{Y} \times \mathrm{T})$ is non- significant on elongation.

The comparison of mean values for yarn elongation for different yarn types by applying Duncan's multiple range test is shown in Table 3a and in Fig.3. The elongation values for Y1 (Siro-spun) and Y2 (two fold) are 6.48 and $6.11 \%$, respectively. It is clear from the results that elongation of Siro-spun yarn is more as compared to that of two fold yarn. These results are in accordance with the findings of earlier researchers that the Siro-spun yarn had better yarn elongation (\%) and tenacity than two plied yarn at all twist multipliers (Temel and Celik, 2010; Sun and Cheng, 2000)

Duncan's multiple range test and the comparison of individual treatment means concerning to yarn elongation (\%) for different twist multiplier ( $\mathrm{T}$ ) is given in Table $3(\mathrm{a})$. The highest value of yarn elongation was noted for T3 i.e., 6.46(\%) followed by 6.24 and 6.18 (\%) for $\mathrm{T} 2$ and $\mathrm{T} 1$, respectively. These results differ significantly from each other and match with the observations that the increase of twist factor and spindle speed increased the elongation percentage of yarn (Shabir, 2008; Subramaniam et al., 1989; Sharma et al., 1987).

\section{Conclusion}

The present research was planned to explore qualitative analysis of Siro-spun and two fold yarns with special reference to their tensile properties. The respective yarns of same count i.e., 20s were made for various twist levels. The findings disclosed the fact that all yarn tensile properties i.e., single end strength, breaking length (RKM) and elongation percentage were better for Siro-spun yarn as compared to that of two fold yarn with increasing twist levels. This is because of the better handling of fibres into the yarn surface in Siro yarn 
spinning technique which increases the compactness of the yarn and ultimately enhances its tensile properties.

\section{References}

ASTM Committee. 2008. Standard Test Method for Measurement of Yarn. ASTM Designation D: 225602. American Society for Test \& Material, Philadelphia, U.S.A.

Bashir, M. S. 2010. Comparison of Hybrid Folded Cotton Yarn Quality from Different System Spun Yarns and its Effect upon Knitted Fabric. M.Sc. Thesis, Department of Fiber Technology, University. of Agriculture, Faisalabad, Pakistan.

Cheng, K.P.S., Yuen, C.H. 1997. Siro and two-fold yarns. Research Journal of Textile and Apparel 1: $64-70$.

Huo, L. 2008. Study on siro spunning system to reduce the hairiness of yarn. Modern Applied Science, 2:133-138.

Lei, C. H. 2003. Continuous spun-like textured yarn processed with various plied filaments and different stages of Emery wheels. Textile Research Journal, 73: 1046-1051.

Montgomery, D. C. 2009. Design and Analysis of Experiments. Arizona State University. ISBN: 9780-470-12866-4.

Palaniswamy, K., Mohamed, P. 2006. Effect of the single-yarn twist and ply to single-yarn twist ratio on the hairiness and abrasion resistance of cotton two-ply yarn. Autex Research Journal, 6: 59-71.

Rosiak, D., Przybyl, K. 2004. Twisting of multi-folded yarns and threads manufactured by means of new spinning technologies. Autex Research Journal, 4:113-117.

Shabir, M. 2008. Optimization of Twist Ratio of Single Yarn and Ply to Single Yarn for Different Counts. M.Sc. Thesis, Department of Fiber Technology, University of Agriculture, Faisalabad, pp. 25-30.

Sharma, I. C., Gupta, N. K., Agarwal, B. R., Patnaik, N. R. 1987. Effect of twist factor and stitch length of open-end spun cotton yarn on properties of rib knitted fabrics. Textile Research Journal, 57: 73-81.

Soltani, P., Johari,M.S. 2012. A study on siro, solo, compact and conventional ring spun yarns. Part I: structural and migratory properties of the yarns. The Journal of the Textile Institute, 103: 622-628.

Subramaniam, V., Srinivasamoorthi, V.R., Mohamed, A. P. 1989. Effect of processing parameters on the properties of double-rove spun yarn produced on a short staple spinning system. Textile Research Journal, 59: 762-767.

Sun, M. N., Cheng, K. P. S. 2000. Structure and properties of cotton siro spun yarn. Textile Research Journal, 70: 261-268.

Temel, E., Celik, P. 2010. A research on spinnability of $100 \%$ polyester and polyester cotton blend siro spun yarns. Journal of Textile and Apparel, 20: $23-29$.

Xuzhong, Su., Weidong, G., Xinjin, L., Chunping, X., Bojun, X. 2015. Rsearch on the compact siro spun yarn structure. Fibers \& Textiles in Eastern Europe, 3: 54-57. 